\title{
The influence of temperature on the small-strain viscous deformation mechanics of snow: a comparison with polycrystalline ice
}

\author{
Garlo SCAPOZZA, ${ }^{1,2}$ Perry A. BARTelT ${ }^{2}$ \\ ${ }^{1}$ Institute for Geotechnical Engineering, Swiss Federal Institute of Technology, ETH-Hönggerberg, CH-8093 Zürich, Switzerland \\ E-mail: c.scapozza@igt.baug.ethz.ch \\ ${ }^{2}$ WSL Swiss Federal Institute for Snow and Avalanche Research (SLF), Flüelastrasse 11, CH-7260 Davos Dorf, Switzerland
}

\begin{abstract}
Glen's law is commonly used to model the viscous deformation of polycrystalline ice. It is a power law that relates stress to viscous strain rate and contains three material parameters: $n$, a power-law exponent, $Q$, an activation energy, and $A_{0}$, a material constant. Because polycrystalline ice is the constituent material of snow, it is to be expected that the viscous deformation mechanics of snow are related to the viscous behaviour of polycrystalline ice, especially under small strains and low strain rates when kinematic effects in the ice matrix like bond breakage, bond formation and grain sliding are of secondary importance. Based on 64 deformation-controlled compression tests on fine-grained snow in the density range $200-430 \mathrm{~kg} \mathrm{~m}^{-3}$ and temperature range $T=-20$ to $-2{ }^{\circ} \mathrm{C}$, we show that Glen's law - with material parameters similar to those for polycrystalline ice - can be applied to model the viscous deformation of high-density snow. However, the values of the ice material parameters are valid for densities above a relatively low density of $400 \mathrm{~kg} \mathrm{~m}^{-3}$; they are not valid for snow with densities below $360 \mathrm{~kg} \mathrm{~m}^{-3}$. We present the variation of $n, Q$ and $A$ for snow as a function of density and temperature. A possible explanation for this behaviour is that the ice grains in low-density snow are less constrained. Therefore, deformation mechanisms, such as grain-boundary sliding, increase in overall importance, leading to smaller $n$ values and higher activation energies, $Q$. Although the material behaviour of low-density snow can be accurately modelled using a power law, the power-law parameters depart substantially from those of polycrystalline ice. The large variation of $n$ and $Q$ with temperature and density underscores the difficulty of predicting snow avalanches.
\end{abstract}

\section{INTRODUGTION}

Field tests show that temperature is an important factor for avalanche formation (Perla, 1977). It is believed that an increase in temperature causes an acceleration of grain sintering and therefore an increase in snow-cover strength. Conversely, at higher temperatures creep processes are accelerated, and strain and deformation rates increase. This results in a decrease in stiffness of the snow cover that can activate the development of local stress concentrations, which are responsible for avalanche formation (Bader and Salm, 1990). These two processes - work hardening through sintering, and development of stress concentrations - are in competition and are believed to determine the stability of the snow cover. Knowledge about the temperature-dependent viscoelastic behaviour of the snow layers and the intergranular sintering processes is therefore of primary importance for a better understanding of avalanche formation.

Our research deals with the influence of temperature, snow density and microstructure on the viscous behaviour of snow. Previous data have been reported by Mellor (1975) and Voytkovskiy (1977). These works provide an overview of the mechanical properties of snow. However, the reported data are mostly from mono-axial creep tests (constant load) at only a few different temperatures. Mellor and Smith (1966) reported results of creep tests on snow with densities of 440-
$830 \mathrm{~kg} \mathrm{~m}^{-3}$ and temperatures of -34.5 to $-0.5^{\circ} \mathrm{C}$. An apparent activation energy $Q$ was determined using an Arrhenius law. The calculated values $44.8 \mathrm{~kJ} \mathrm{~mol}^{-1}<Q<74.5 \mathrm{~kJ} \mathrm{~mol}^{-1}$ are of the same order of magnitude as the values for self-diffusion in ice $\left(Q \approx 70 \mathrm{~kJ} \mathrm{~mol}^{-1}\right)$ (Barnes and others, 1971). Mellor and Smith (1966) also reported values of the apparent activation energy, varying between 87 and $100 \mathrm{~kJ} \mathrm{~mol}^{-1}$, found by Yosida and others (1955) for low-density snow $\left(170 \mathrm{~kg} \mathrm{~m}^{-3}<\rho\right.$ $<250 \mathrm{~kg} \mathrm{~m}^{-3}$ ) and in the temperature range $-25^{\circ} \mathrm{C}<T<$ $-3^{\circ} \mathrm{C}$. However, because Mellor's tests were conducted at only one stress level $(\sigma=50 \mathrm{kPa})$, an evaluation of the stress-strain-rate relationship as a function of temperature and density could not be carried out. More recently, McClung (1996) and Schweizer (1998) have reported the results of shear tests on dry fine-grained alpine snow. In both works, the relationship between strain rate, yield stress and failure stress has not been investigated in terms of a power law (Equation (1)), as is usual in polycrystalline ice. Also, no attempt was made to quantify the influence of temperature using an Arrhenius law. A statement about the activation energy is therefore missing in both works.

The viscous behaviour of snow has been modelled using a power law (Equation (1)) in the microstructure-based constitutive models published by Mahajan and Brown (1993) and Bartelt and von Moos (2000). However, both the activation energy $\left(Q=120 \mathrm{~kJ} \mathrm{~mol}^{-1}\right.$ for $T>-10^{\circ} \mathrm{C} ; Q=78 \mathrm{~kJ} \mathrm{~mol}^{-1}$ for 


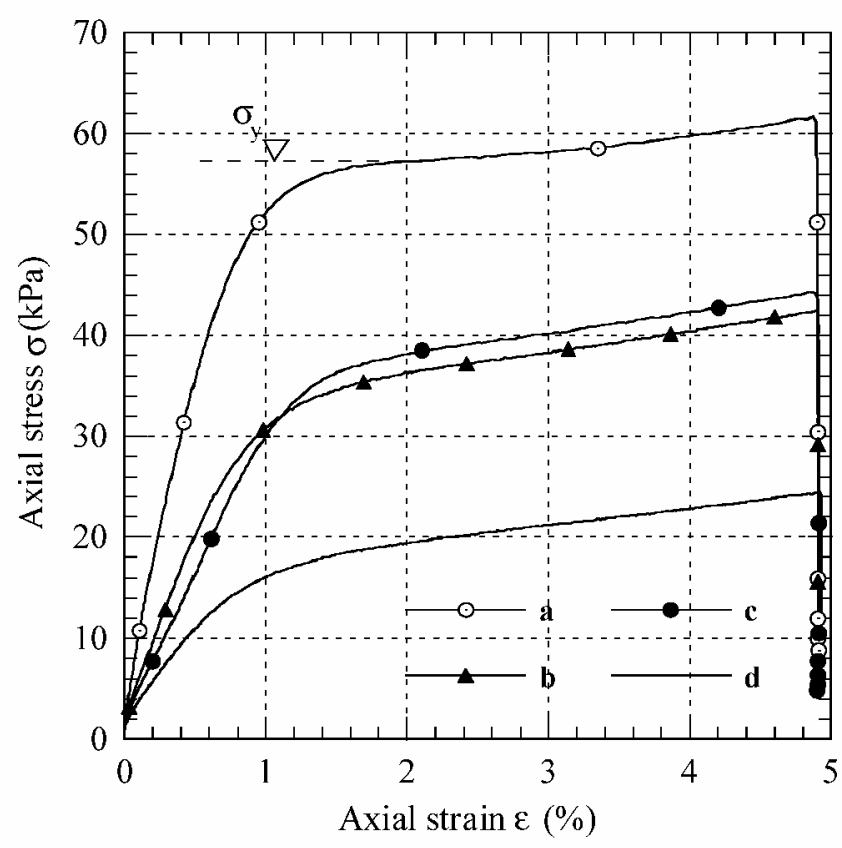

Fig. 1. Stress-strain curves for four different temperatures and strain rates, density $\rho=272 \mathrm{~kg} \mathrm{~m}^{-3}$. (a) $\mathrm{T}=-18.9^{\circ} \mathrm{C}, \dot{\varepsilon}=$

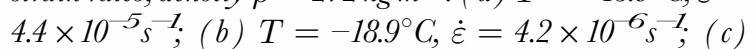
$\mathrm{T}=-5.0^{\circ} \mathrm{C}, \dot{\varepsilon}=4.4 \times 10^{-5} \mathrm{~s}^{-1} ;$ (d) $\mathrm{T}=-5.0^{\circ} \mathrm{C},=$ $4.2 \times 10^{-2} s^{-1}$. The yield stress, $\sigma_{y}$ is indicated.

$T<-10^{\circ} \mathrm{C}$ ) and the exponent $n$ for polycrystalline ice have been employed $(n=3.0)$. Because experimental data were missing, the exponent $n$ and the activation energy $Q$ were assumed to be temperature- and density-independent. As will be shown, this does not agree with our experimental data.

The goal of this paper is to quantify the temperature and density dependence on the viscous behaviour of snow. A power law will be used to describe the relationship between strain rate and yield stress; the values of the activation energy $Q$ and of the exponent $n$ will therefore be quantified. The yield stress $\left(\sigma_{y}\right)$ is defined here as the stress at which a steady-state viscous deformation is reached (Fig. 1). The data analysis is based on test results of mono-axial deformation controlled compression tests on fine-grained alpine snow with a density of $200-430 \mathrm{~kg} \mathrm{~m}^{-3}$ at temperatures ranging between $T=-20^{\circ} \mathrm{C}$ and $T=-2^{\circ} \mathrm{C}$. The reported test results are part of a larger investigation (200 tests) in which samples of different density $\left(190 \mathrm{~kg} \mathrm{~m}^{-3}<\rho<430 \mathrm{~kg} \mathrm{~m}^{-3}\right)$ were also tested in both confined and unconfined compression at $T=-12^{\circ} \mathrm{C}$ and in the same range of strain rates. An important result of this work (Bartelt and von Moos, 2000) is that the axial yield stress is independent of the applied confining pressure. In the tests with low-density snow ( $\rho=$ $200 \mathrm{~kg} \mathrm{~m}^{-3}$ ), we observed that when the confining pressure exceeds a critical value, which is probably dependent on density, densification effects (building of new bonds) take place and influence the response of the sample, leading to a rapid increase of the axial yield stress. However, these critical pressures are much higher than those encountered in the natural snow cover. Subsequently, only unconfined tests were performed to establish the influence of the temperature on the viscoelastic behaviour of snow. In the larger test series, strain-rate controlled tests with unloading steps were also performed, in order to determine the distribution of elastic, anelastic and viscous strain as a function of the total strain, density, temperature and strain rate. In this paper, we limit
Table 1. Test parameters. In all, 64 tests were completed. For each density, four different strain rates were applied at four different temperatures

\begin{tabular}{lcccc}
\hline & \multicolumn{4}{c}{ Test identification No. (density) } \\
& $01 \mathrm{v04}$ & Olv02 & O1w01 & 01v03) \\
& $\left(200 \mathrm{~kg} \mathrm{~m}^{-3}\right)$ & $\left(270 \mathrm{~kg} \mathrm{~m}^{-3}\right)$ & $\left(360 \mathrm{~kg} \mathrm{~m}^{-3}\right)$ & $\left(430 \mathrm{~kg} \mathrm{~m}^{-3}\right)$ \\
\hline Strain rate $\left(\mathrm{s}^{-1}\right)$ & $1.1 \times 10^{-6}$ & $4.2 \times 10^{-6}$ & $1.1 \times 10^{-5}$ & $4.4 \times 10^{-5}$ \\
Total test duration $(\mathrm{min})$ & 800 & 243 & 120 & 64 \\
Temperature $\left({ }^{\circ} \mathrm{C}\right)$ & -19 & -11 & -4 & -2 \\
\hline
\end{tabular}

our attention to the temperature- and density-dependent viscous behaviour of snow. The relationship between strain rate and yield stress is quantified as a function of temperature and density. A finite-element model, assuming a stationary viscous solution for the governing equilibrium equations (Bartelt and Christen, 1999), has been developed. Some numerical results, demonstrating the application of the experimental results, will briefly be reported.

\section{TEST PROGEDURE}

The temperature-dependent tests were performed using a deformation-controlled triaxial apparatus (Bartelt and von Moos, 2000). In total, 64 tests in compression (4 densities, 4 temperatures, 4 strain rates) were completed. For all tests, natural fine-grained $(d<0.2 \mathrm{~mm})$ alpine snow was used. This snow was collected nearWeissfluhjoch, Davos, Switzerland, at an elevation of approximately $2540 \mathrm{~m}$. At each collection time, a pit was dug in the snow, and a homogeneous layer with the desired density was identified. Portions of this layer were then extracted without damaging the snow, placed in a sealed container and stored at $-12{ }^{\circ} \mathrm{C}$. Testing was normally started within a few days after collection. The test samples, cylindrical specimens $126 \mathrm{~mm}$ long and $58 \mathrm{~mm}$ in diameter, were cut from the stored snow blocks so that the long axis of the sample was parallel to the layering. To allow the specimen to adjust to the desired test temperature (Table 1), the sealed containers were placed in the test room for a few hours. During this time, the temperature of the snow block was controlled. The specimens were not cut until the test temperature was reached. Because the investigated snow was well rounded and fine-grained, even low-density samples maintained their form during testing.

The specimens were compressed to an axial strain of $5 \%$. A relaxation period of $45 \mathrm{~min}$ was included after $5 \%$ was reached, i.e. the straining was stopped and the stress relaxation was measured. The approximate values of the test parameters are given in Table 1.

\section{TEST RESULTS}

Figure 1 shows the stress-strain behaviour for one density, $\rho=272 \mathrm{~kg} \mathrm{~m}^{-3}$. The stress increases with increasing strain, although not linearly, until an approximately constant yield stress is reached (curve a). With increasing strain, work hardening takes place, probably due to densification effects (building of new bonds). The rapid drop of stress at the final strain of $5 \%$ is due to relaxation. The yield stress $\sigma_{y}$ increases with increasing strain rate and decreases with increasing tempera- 


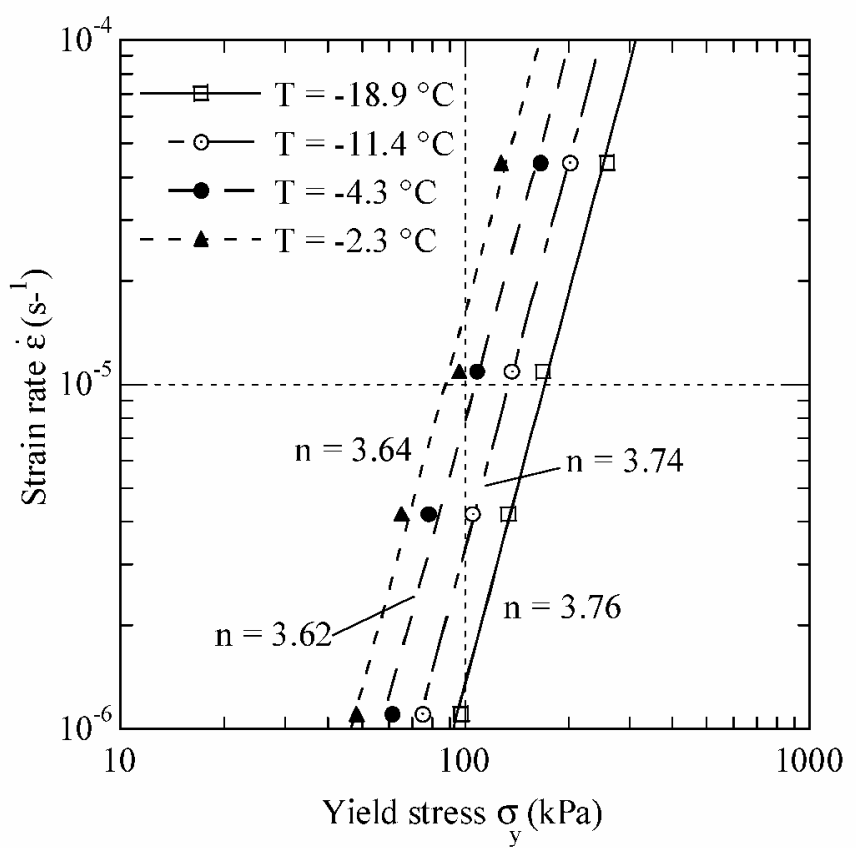

Fig. 2. Applied axial strain rate vs axial yield stress; $n$ is the exponent of the power law (Equation (1)). Density $\rho=$ $423 \mathrm{~kg} \mathrm{~m}^{3}$.

ture. The relationship between yield stress, strain rate and temperature can be expressed as a power law (Glen, 1955) based on the Arrhenius law:

$$
\dot{\varepsilon}=A_{0} \mathrm{e}^{-\frac{Q}{R T}}\left(\sigma_{y}\right)^{n}=A\left(\sigma_{y}\right)^{n},
$$

where $\dot{\varepsilon}$ is the applied strain rate $\left(\mathrm{s}^{-1}\right), A_{0}$ is a density-

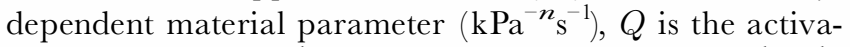
tion energy $\left(\mathrm{kJ} \mathrm{mol}^{-1}\right), R$ is the gas constant $\left(\mathrm{kJ} \mathrm{mol}^{-1} \mathrm{~K}^{-1}\right)$, $T$ is the temperature $(\mathrm{K}), \sigma_{y}$ is the resulting yield stress $(\mathrm{kPa})$ and $n$ is a dimensionless exponent.

\section{Stress-strain-rate relationship}

Figure 2 shows the relationship between applied strain rate and yield stress in a $\log -\log$ plot. The best fit to the data, for the investigated strain-rate range $1.1 \times 10^{-6} \mathrm{~s}^{-1}<\dot{\varepsilon}<4.4 \times 10^{-5}$ $\mathrm{s}^{-1}$, is linear. Therefore, the stress-strain-rate relationship obeys the power law (Equation (1)). Note that the exponent $n$ of Equation (1) represents the slope of the plotted lines (Fig. 2). Additional values of the yield stress as a function of strain rate, temperature and density are reported in Table 2.

Consider the influence of temperature and density on the exponent $n$. As shown in Figure 3, for a mean density of $423 \pm 8 \mathrm{~kg} \mathrm{~m}^{-3}$, we found a mean exponent $n=3.69 \pm 0.07$. This value is approximately the same for all four investigated temperatures and agrees well with the values reported for polycrystalline ice (Weertman, 1973). For the investigated densities below $\rho=423 \mathrm{~kg} \mathrm{~m}^{-3}$, the test results show something unexpected. The exponent $n$ is a function of the density and of the temperature, and increases with increasing density. It is higher at lower temperatures. Finally, for low densities $\rho=$ $150-200 \mathrm{~kg} \mathrm{~m}^{-3}$, it seems that $n$ reaches a temperature-independent minimum value of approximately $n=1.7$.

\section{Stress-temperature relationship}

For constant-load creep tests, the following equation (Equation (2)) has often been used to describe the temperature-

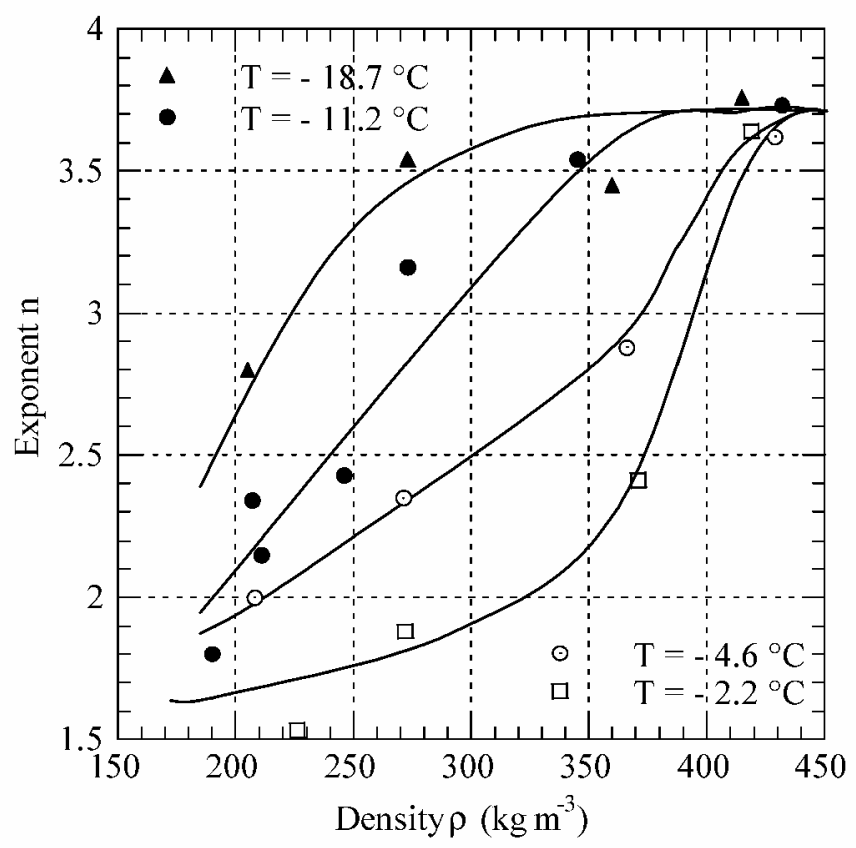

Fig. 3. Temperature and density dependence of the exponent $n$ for strain rates ranging between $\dot{\varepsilon}=1.1 \times 10^{-\sigma_{s}^{-1}}$ and $\dot{\varepsilon}=$ $4.4 \times 10^{-5}-1$.

dependent secondary creep of polycrystalline ice. The exponent $n$ is assumed to be temperature-independent.

$$
\dot{\varepsilon}_{\mathrm{s}}=\dot{\varepsilon}_{0} \mathrm{e}^{-\frac{Q}{R T}}
$$

The reference strain rate is denoted as $\dot{\varepsilon}_{0}=A_{0}(\sigma)^{n}$, where $\sigma$ is the applied stress and $A_{0}$ is a temperature-independent parameter. Thus, the equation cannot be directly employed in our analysis. For our strain-rate controlled tests, the exponent $n$ was found to be temperature-dependent. Therefore, in order to calculate the activation energy $Q$, we have to make use of Equation (1) at two different temperatures $T_{1}$ and $T_{2}$,

$$
\begin{aligned}
& \dot{\varepsilon}=A_{0} \mathrm{e}^{-\frac{Q}{R T_{1}}}\left(\sigma_{y 1}\right)^{n_{1}} \\
& \dot{\varepsilon}=A_{0} \mathrm{e}^{-\frac{Q}{R T_{2}}}\left(\sigma_{y 2}\right)^{n_{2}},
\end{aligned}
$$

where $T_{1}<T_{2}$, $\dot{\varepsilon}$ is the applied strain rate, $\sigma_{y 1}$ and $\sigma_{y 2}$ are

\begin{tabular}{|c|c|c|c|c|c|}
\hline \multirow[t]{2}{*}{ Density } & \multirow{2}{*}{$\begin{array}{c}\text { Tem- } \\
\text { perature }\end{array}$} & \multicolumn{4}{|c|}{ Yield stress $\sigma_{y}$} \\
\hline & & $\begin{array}{c}\dot{\varepsilon}= \\
1.1 \times 10^{-\sigma^{*}}\end{array}$ & $\begin{array}{c}\dot{\varepsilon}= \\
4.2 \times 10^{-6}\end{array}$ & $\begin{array}{c}\dot{\varepsilon}= \\
1.1 \times 10^{-5}\end{array}$ & $\begin{array}{c}\dot{\varepsilon}= \\
4.4 \times 10^{-5}\end{array}$ \\
\hline $\mathrm{kg} \mathrm{m}^{-3}$ & ${ }^{\circ} \mathrm{C}$ & $\mathrm{kPa}$ & $\mathrm{kPa}$ & $\mathrm{kPa}$ & $\mathrm{kPa}$ \\
\hline $415 \pm 3$ & $-18.9 \pm 0.1$ & 97.0 & 133.0 & 168.0 & 258.0 \\
\hline $429 \pm 3$ & $-11.0 \pm 0.1$ & 75.0 & 105.0 & 136.0 & 201.0 \\
\hline $418 \pm 6$ & $-2.3 \pm 0.1$ & 48.4 & 65.6 & 96.1 & 127.0 \\
\hline $360 \pm 2$ & $-18.1 \pm 0.7$ & 47.5 & 79.2 & 97.6 & 138.0 \\
\hline $345 \pm 5$ & $-11.0 \pm 0.0$ & 43.3 & 66.5 & 85.0 & 123.0 \\
\hline $371 \pm 2$ & $-2.1 \pm 0.3$ & 18.6 & 37.9 & 55.1 & 84.1 \\
\hline $272 \pm 5$ & $-18.9 \pm 0.1$ & 25.1 & 36.0 & 48.0 & 67.0 \\
\hline $272 \pm 2$ & $-11.0 \pm 0.1$ & 14.7 & 25.9 & 34.5 & 45.5 \\
\hline $272 \pm 3$ & $-2.1 \pm 0.2$ & 5.3 & 15.8 & 22.2 & 34.6 \\
\hline $205 \pm 2$ & $-18.7 \pm 0.3$ & 4.4 & 9.1 & 9.6 & 15.9 \\
\hline $207 \pm 1$ & $-11.4 \pm 0.3$ & 3.3 & 4.0 & 6.7 & 10.9 \\
\hline $225 \pm 3$ & $-2.3 \pm 0.2$ & 1.7 & 3.3 & 7.2 & 17.0 \\
\hline
\end{tabular}
the measured yield stresses and $n_{1}$ and $n_{2}$ are the calculated

Table 2. Yield stress $\sigma_{y}$ as a function of strain rate, temperature and density

${ }^{*} \dot{\varepsilon}$ is the applied strain rate in $\mathrm{s}^{-1}$. 


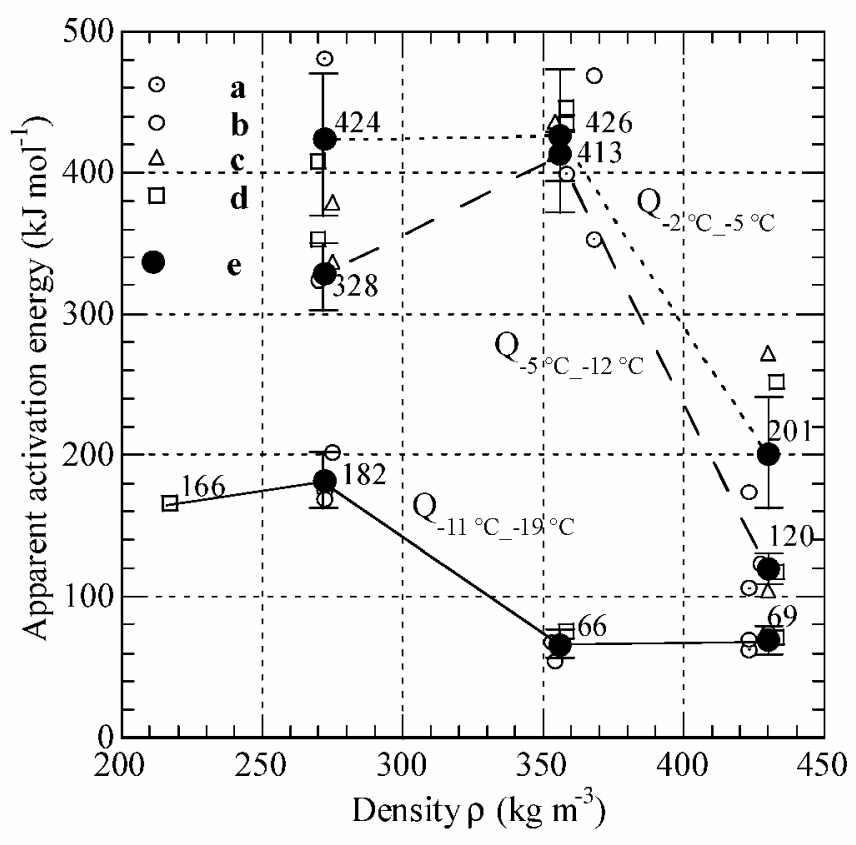

Fig. 4. Temperature and density dependence of the apparent activation energy $Q$ for different strain rates. (a) $\dot{\varepsilon}=1.1 \times 10^{-5} \mathrm{~s}^{-1}$; (b) $\dot{\varepsilon}=4.2 \times 10^{-6} \mathrm{~s}^{-1} ;$ (c) $\dot{\varepsilon}=1.1 \times 10^{-6} \mathrm{~s}^{-1}$; (d) $\dot{\varepsilon}=$ $4.4 \times 10^{-5} \mathrm{~s}^{-1}$; (e) mean value.

exponents. Note that the subscripts 1 and 2 always refer to two distinct temperatures $T_{1}$ and $T_{2}$. The activation energy for the temperature range $T_{1}<T<T_{2}$ is obtained from Equations (3) and (4):

$$
Q=\frac{R\left(n_{1} \ln \sigma_{y 1}-n_{2} \ln \sigma_{y 2}\right)}{\left(\frac{1}{T_{1}}-\frac{1}{T_{2}}\right)} .
$$

Figure 4 shows calculated activation energy as a function of density for three different temperature ranges. As can be seen for a mean density of $423 \pm 8 \mathrm{~kg} \mathrm{~m}^{-3}$, the measured activation energy amounts to $Q=69 \pm 5 \mathrm{~kJ} \mathrm{~mol}^{-1}$ for $-19^{\circ} \mathrm{C}<T$ $<-11^{\circ} \mathrm{C}$. This value agrees well with the data reported for self-diffusion of vacancies through the lattice in polycrystalline ice (Barnes and others, 1971). In the temperature range $-5^{\circ} \mathrm{C}<T<-2^{\circ} \mathrm{C}$, we measured $Q=201 \pm 80 \mathrm{~kJ} \mathrm{~mol}^{-1}$. This increase in the activation energy at high temperatures $(T>$ $-10^{\circ} \mathrm{C}$ ) has also been reported for polycrystalline ice (Budd and Jacka, 1989; Morgan, 1991). Because the calculated activation energies for $T>-11^{\circ} \mathrm{C}$ cannot be directly related to a single deformation process (e.g. self-diffusion of vacancies through the lattice), we speak of an apparent activation energy when $Q_{\text {calculated }} \neq Q_{\text {selfdiffusion. }}$. For a mean density of $360 \pm 10 \mathrm{~kg} \mathrm{~m}^{-3}$ and a temperature range $-19^{\circ} \mathrm{C}<T<$ $-11^{\circ} \mathrm{C}$, the apparent activation energy is $Q=66 \pm 9 \mathrm{~kJ} \mathrm{~mol}^{-1}$. This value can also be related to self-diffusion in ice. Note, however, that as soon as the temperature exceeds $-10^{\circ} \mathrm{C}$, the apparent activation energy increases to a very large value of $Q=413-426 \mathrm{~kJ} \mathrm{~mol}^{-1}$. This amount does not reflect the behaviour expected of polycrystalline ice at this strain-rate and temperature range. Thus, for a density of $\rho=$ $360 \mathrm{~kg} \mathrm{~m}^{-3}$ at temperatures above $-4.8^{\circ} \mathrm{C}$, we observed a clear decrease in the exponent $n$, i.e. $n$ decreases from $n=$ 3.6 to values smaller then 2.4 (Fig. 3). Finally, for a density of $\rho=272 \pm 5 \mathrm{~kg} \mathrm{~m}^{-3}$, at temperatures below $-11^{\circ} \mathrm{C}$, the calculated apparent activation energy $Q=182 \pm 18 \mathrm{~kJ} \mathrm{~mol}^{-1}$ does not agree with the values reported for self-diffusion in poly-

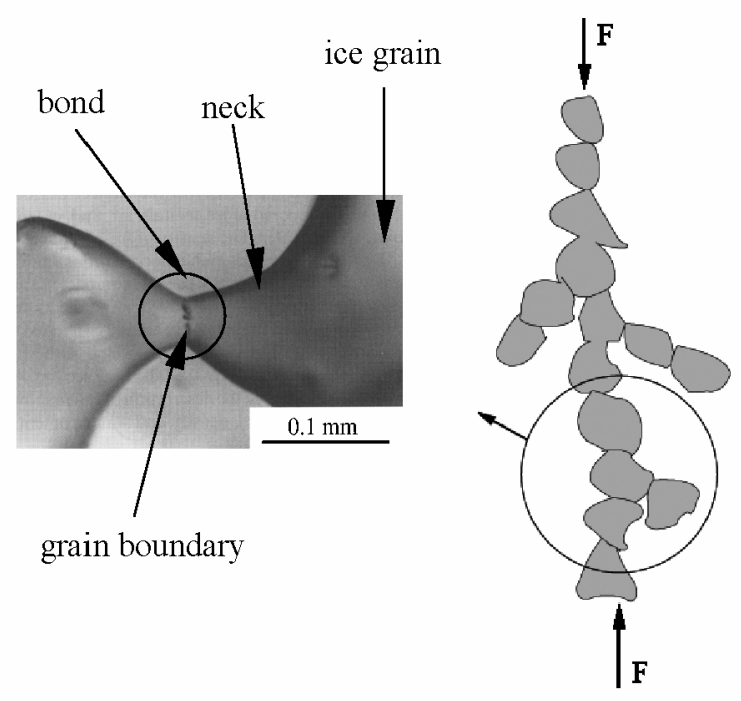

Fig. 5. The load-bearing "chain" concept of Gubler (1978), with a detailed picture of a neck formed between grains (from Colbeck, 1998). The grain boundary is also depicted.

crystalline ice. For temperatures above $-11^{\circ} \mathrm{C}$ we calculate a mean value of the apparent activation energy ranging between 328 and $424 \mathrm{~kJ} \mathrm{~mol}^{-1}$.

\section{DISGUSSION OF THE TEST RESULTS}

The bulk behaviour of snow under load at small strains $(\varepsilon<1-2 \%)$ is primarily due to the deformation mechanics of the granular ice skeleton, which is composed of polycrystalline ice. The ice skeleton carries the applied load in "force chains" (Voytkovskiy, 1977; Gubler, 1978; Brown, 1980), which consist of snow grains connected at bonds (Fig. 5). In our tests, both grain-size and grain shape are similar for the whole range of densities. All of the snow selected was granular, with well-bounded grains of approximately $0.2 \mathrm{~mm}$ diameter. The main difference between high and low density can be seen by evaluating the coordination number $N_{3}$, which describes the number of bonds per grain (Gubler, 1978). This varies from $N_{3}<2.5$ for $\rho=200 \mathrm{~kg} \mathrm{~m}^{-3}$ to $N_{3}=$ 4.0 for a snow density $\rho=430 \mathrm{~kg} \mathrm{~m}^{-3}$ (Alley, 1986). For lowdensity snow $\left(\rho<\sim 400 \mathrm{~kg} \mathrm{~m}^{-3}\right)$ with low coordination numbers, the grains are not highly constrained and can move relative to each other in a shearing motion. Therefore, bonds in low-density snow are subjected to larger shearing stresses (Voytkovskiy, 1977). In high-density snow, on the other hand, the grains are constrained and no longer free to move relative to each other. This means that the bonds between grains are mostly subjected to compressive deformation modes, i.e. the shearing stresses tend to vanish. Thus, high-density snow $\left(\rho \geq 430 \mathrm{~kg} \mathrm{~m}^{-3}\right)$ shows in principle the same viscous behaviour as polycrystalline ice. The values of the exponent $n$ and of the apparent activation energy $Q$ agree well with the values for polycrystalline ice reported in previous works (Barnes and others, 1971; Weertman, 1973; Budd and Jacka, 1989; Morgan, 1991). In conclusion, we found that snow with density $\rho>\sim 400 \mathrm{~kg} \mathrm{~m}^{-3}$ has a power-law exponent $n$ and activation energy $Q$ similar to those of polycrystalline ice. The pre-exponent parameter $A$ (Fig. 6) converges to the experimental values calculated using data of mono-axial compression tests on high-density firn and porous ice $\left(659 \mathrm{~kg} \mathrm{~m}^{-3} \leq \rho \leq 912 \mathrm{~kg} \mathrm{~m}^{-3}\right)$ performed by Jacka (1994). 


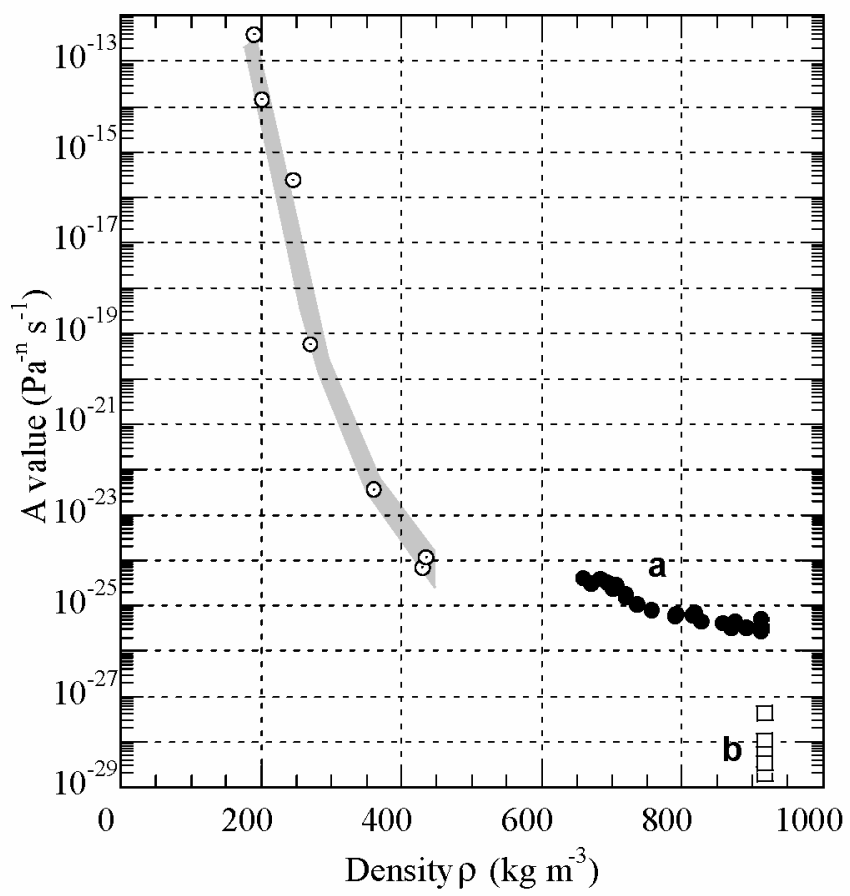

Fig. 6. Material parameter A (Equation (1)) as a function of density, for $T=-12^{\circ} \mathrm{C}$ and for strain rates ranging between $\dot{\varepsilon}=1.1 \times 10^{-6} \mathrm{~s}^{-1}$ and $\dot{\varepsilon}=4.4 \times 10^{-5} \mathrm{~s}^{-1}$. The values are compared with (a) the A values for high-density firn and porous ice $\left(659 \mathrm{~kg} \mathrm{~m}^{-3} \leq \rho \leq 912 \mathrm{~kg} \mathrm{~m}^{-3}\right)$ calculated using the test results of mono-axial compression tests $\left(T=-3.3^{\circ} \mathrm{C}\right.$, octahedral shear stress $=0.2 \mathrm{MPa}$ ) reported by facka (1994); the test results were normalized to $T=-12^{\circ} \mathrm{C}$ using $Q=$ $160 \mathrm{~kJ} \mathrm{~mol}^{-1}$; (b) the A values for polycrystalline ice calculated with the parameters $A_{0}, Q$ and $n$ reported by Barnes and others (1971) for $T=-12^{\circ} \mathrm{C}$.

These data are also displayed in Figure 6 along with data for polycrystalline ice reported by Barnes and others (1971).

Several explanations can be proposed to show why the behaviour of snow with a density $\rho<\sim 400 \mathrm{~kg} \mathrm{~m}^{-3}$ does not reflect the properties of polycrystalline ice. Barnes and others (1971) provided a physical interpretation of the increase in activation energy in polycrystalline ice at $T>-10^{\circ} \mathrm{C}$. They concluded that the formation of a liquid layer at the triple point and grain-boundary sliding serve as accommodation processes for dislocation creep occurring within the ice grain. Further, they concluded that the calculated activation energy of $120 \mathrm{~kJ} \mathrm{~mol}^{-1}$ does not refer to a single specific creep process. However, they stress the fact that the creep behaviour of normal-grained polycrystalline ice $(d \sim 1 \mathrm{~mm})$ is primarily determined by creep within the ice grains because the creeprate stress dependence remains approximately cubic over the whole range of the investigated temperatures. In a more recent work, Goldsby and Kohlstedt (1997) attempt to show the influence of grain-size sensitive creep mechanisms on the flow of fine-grained ice produced in the laboratory (grainsize $d$ in the range $3 \mu \mathrm{m} \leq d \leq 90 \mu \mathrm{m}$ ) at strain rates $\dot{\varepsilon} \geq$ $1 \times 10^{-8} \mathrm{~s}^{-1}$. Note that this kind of ice does not occur in naturally occurring ice or snow masses. They found an exponent $n=1.8$ and an activation energy $Q=49 \pm 1 \mathrm{~kJ} \mathrm{~mol}^{-1}$ for strain rates between $10^{-8} \mathrm{~s}^{-1} \leq \dot{\varepsilon} \leq 10^{-6} \mathrm{~s}^{-1}$, grain-sizes in the range $26 \mu \mathrm{m} \leq d \leq 40 \mu \mathrm{m}$ in the temperature range $-58^{\circ} \mathrm{C}$ $<T<-37^{\circ} \mathrm{C}$. Goldsby and Kohlstedt concluded on the basis of the mechanical results and the microstructural investigations (environmental scanning electron microscopy (ESEM) micrograph analysis), that grain-boundary sliding accommodated by dislocation motion is the rate-limiting process in this $n=1.8$ regime.

These works on polycrystalline ice can be used to help us understand the behaviour of snow. For the density range $200 \mathrm{~kg} \mathrm{~m}^{-3} \leq \rho \leq 360 \mathrm{~kg} \mathrm{~m}^{-3}$, we found

(i) A decrease in the power-law exponent $n$. With decreasing density, we found smaller $n$ values (Fig. 3).

(ii) An increase in apparent activation energy with decreasing density (Fig. 4).

(iii) The nrho isolines (Fig. 3) are strongly dependent on temperature.

This behaviour is not similar to that of polycrystalline ice with grain-size typical of those found in the natural ice masses. Because the applied strains were small at moderate strain rates, effects like bond formation, bond breakage and large-scale inter-particle slip cannot be responsible for this behaviour. In the cited ice literature (Barnes and others, 1971; Goldsby and Kohlstedt, 1997), smaller $n$ values and higher activation energies $Q$ are related to deformation mechanisms occurring at or near the grain boundaries, which accommodate intra-granular dislocation creep (Barnes and others, 1971) or represent the dominant creep mechanisms (Goldsby and Kohlstedt, 1997). In light of this fact, we suppose that deformation mechanisms occurring at or near the grain boundary are more active in low-density snow. An indication that for low-density snow $\left(\rho<200 \mathrm{~kg} \mathrm{~m}^{-3}\right)$ grain-boundary sliding accommodated by dislocation motion is the rate-limiting process is that the value of $n=$ 1.7 is approximately temperature-independent, as noted by Goldsby and Kohlstedt (1997), although at a much lower temperature range. These conclusions are also supported by the mechanical microstructural model of Voytkovskiy (1977), which assumes that in low-density snow the grain-boundary region is subjected to larger shear stresses.

For high-density snow $\left(\rho=430 \mathrm{~kg} \mathrm{~m}^{-3}\right)$ at temperatures ranging between $-19^{\circ} \mathrm{C} \leq T \leq-2^{\circ} \mathrm{C}$, we determined a temperature-independent exponent $n=3.6$ and apparent activation energies according to the values found for normalgrained polycrystalline ice. Therefore, we suppose that for high-density snow, dislocation creep is the rate-controlling process.

\section{NUMERICAL MODEL}

In order to apply the experimental results in numerical models (Bartelt and Christen, 1999; Bartelt and Lehning, 2002), the nrho and Qrho isolines (Figs 3 and 4) must be parameterized. We found that

$$
n=a \rho^{2}+b \rho+c,
$$

where

$$
\begin{aligned}
& a=1.08 \times 10^{-6} T^{2}-5.67 \times 10^{-4} T+7.40 \times 10^{-2} \\
& b=-5.87 \times 10^{-4} T^{2}+3.06 \times 10^{-1} T-3.98 \times 10^{1} \\
& c=6.22 \times 10^{-2} T^{2}-3.22 \times 10^{1} T+4.17 \times 10^{3}
\end{aligned}
$$

The material parameter $A$ (Fig. 6), which is a function of density and temperature, is

$$
A=3.61 \times 10^{7} \rho^{-7.4} \quad \text { for } \quad T=-12^{\circ} \mathrm{C} .
$$


$A$ is a pre-exponential constant (Equation (1)) in $\left(\mathrm{MPa}^{-n} \mathrm{~s}^{-1}\right)$, which can be scaled to another temperature according to (Sinha, 1979)

$$
A_{1}\left(T_{1}\right)=\frac{A_{2}\left(T_{2}\right)}{S_{1,2}},
$$

where $S_{1,2}$ is a shift function given by

$$
S_{1,2}=\exp \left[\frac{Q}{R}\left(\frac{1}{T_{1}}-\frac{1}{T_{2}}\right)\right] .
$$

$Q$ is the activation energy for the corresponding temperature range $T_{1} \leq T \leq T_{2}$ and density $\rho$, and $R$ is the gas constant; $T_{1}$ and $T_{2}$ are the temperatures $(\mathrm{K})$. Note that the power-law relation for $A$ (Equation (7)) is similar to the experimentally defined equations for unconfined compressive strength of high-density snow $\left(500 \mathrm{~kg} \mathrm{~m}^{-3}<\rho<600 \mathrm{~kg} \mathrm{~m}^{-3}\right)$ reported by Russell-Head and others (1984).

As shown in Figure 4, there is a large variation of the apparent activation energy $Q$ with temperature and density. As noted by Budd and Jacka (1989) for polycrystalline ice, it is difficult to describe the temperature dependence of creep using the concept of activation energy. This undertaking is more difficult for snow, because its density dependence has to be taken into account. Our attempts to describe the variation of the apparent activation energy $Q$ with temperature and density using a mathematical relationship valid for all temperatures and densities have failed. For the numerical model, we used the mean values of $Q$ as reported in Figure 4. For intermediate densities, i.e. densities between those investigated, we linearly interpolated the experimental results.

The relationships presented above (Equations (6-9)) were employed in a plane-strain constitutive law for steadystate creep, used by Bader and Salm (1990)

$$
\sigma_{i j}=[N]\left(\dot{\varepsilon}_{i j}+\frac{\dot{\varepsilon}_{l l} \delta_{i j}}{m-2}\right)
$$

where

$$
[N]=\left[\begin{array}{ccc}
\eta & 0 & 0 \\
0 & \eta & 0 \\
0 & 0 & \frac{\eta}{2}
\end{array}\right],
$$

$\eta$ is a stress-, density- and temperature-dependent viscosity

$$
\eta=\frac{1}{A_{0} \mathrm{e}^{-\frac{Q}{R T}} \sigma^{n-1}}
$$

and $m$ is the inverse of the viscous analogue of Poisson's ratio.

The parameter $m$ was set to $m=\infty$, i.e. the viscous analogue of Poisson's ratio was set to zero, because only the deviatoric component of the stress tensor was considered. Thus, the strain directions $\dot{\varepsilon}_{x}, \dot{\varepsilon}_{y}$ and $\gamma_{x y}$ and the stress components $\sigma_{x}$, $\sigma_{y}$ and $\tau_{x y}$ are assumed to be independent. This assumption accurately reflects the observed behaviour during confined and unconfined triaxial tests (Scapozza and Bartelt, unpublished information): (1) The axial yield stress is independent of the applied confining pressure; (2) non-zero values of Poisson's ratio occur only after a critical strain, denoting the onset of work hardening. This critical strain is reached after yielding. Furthermore, the assumption that the shear viscosity is related to the normal viscosity $\left(\eta_{\text {shear }}=\eta_{\text {compression }} / 2\right)$ is hypothetical for the present application and must be proved by separate compression and shear tests under the same test conditions (temperature, strain rate and density).

The constitutive law given by Bader and Salm (1990) was introduced into a finite-element model. In a first step, the stress state is determined from an elastic calculation.

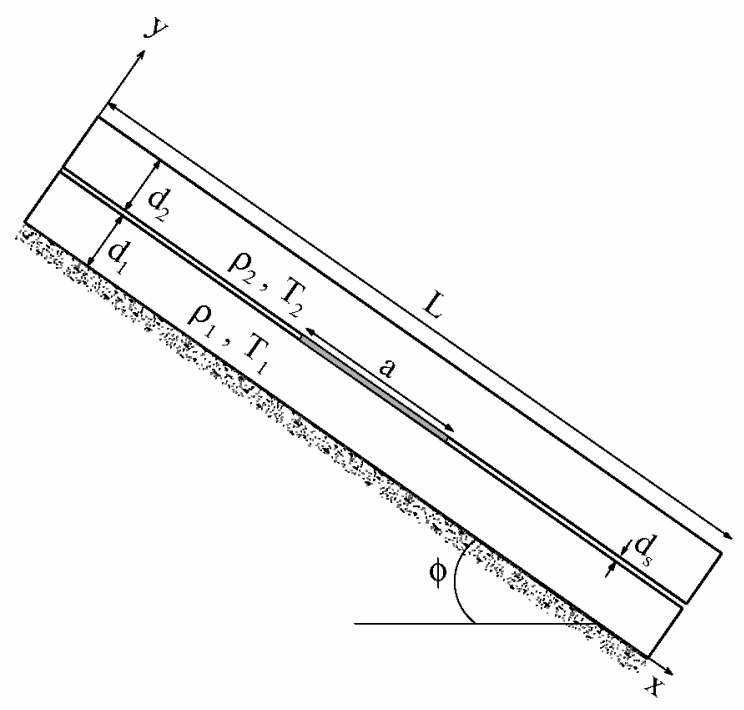

Fig. 7. Weak-layer finite-element model. $L=50 \mathrm{~m}$ is the length of the slope, $a=8 \mathrm{~m}$ is the length of the weak layer and $\phi=35^{\circ}$ is the inclination. The snow cover is composed of two layers with $d_{1}=d_{2}=1.0 \mathrm{~m}$ and a very thin weak layer with $d_{\mathrm{s}} \rightarrow 0 \mathrm{~m}$. Densities and temperatures are $\rho_{1}=$ $400 \mathrm{~kg} \mathrm{~m}^{3}, \rho_{2}=200 \mathrm{~kg} \mathrm{~m}^{-3}, T_{1}=-5^{\circ} \mathrm{C} . T_{2}$ varies between $T_{2}=-12^{\circ} \mathrm{C}$ and $T_{2}=-3^{\circ} \mathrm{C}$.

Then the steady-state strain rates are determined according to Equation (10). An application of the model is to determine stress and strain-rate concentrations around a weak layer of given length $a$ (Fig. 7), as a function of overburden snow and temperature. Figure 8 plots the strain-rate concentration along the weak layer as a function of temperature. The simulations show that an increase in temperature of $9^{\circ} \mathrm{C}$ can produce an increase in the peak strain rate of about three orders of magnitude.

A future development of the finite-element model will consider the viscoelastic behaviour of snow. Work-hardening effects due to large volume changes (20\% strain) will also be considered. The present model does not consider age-

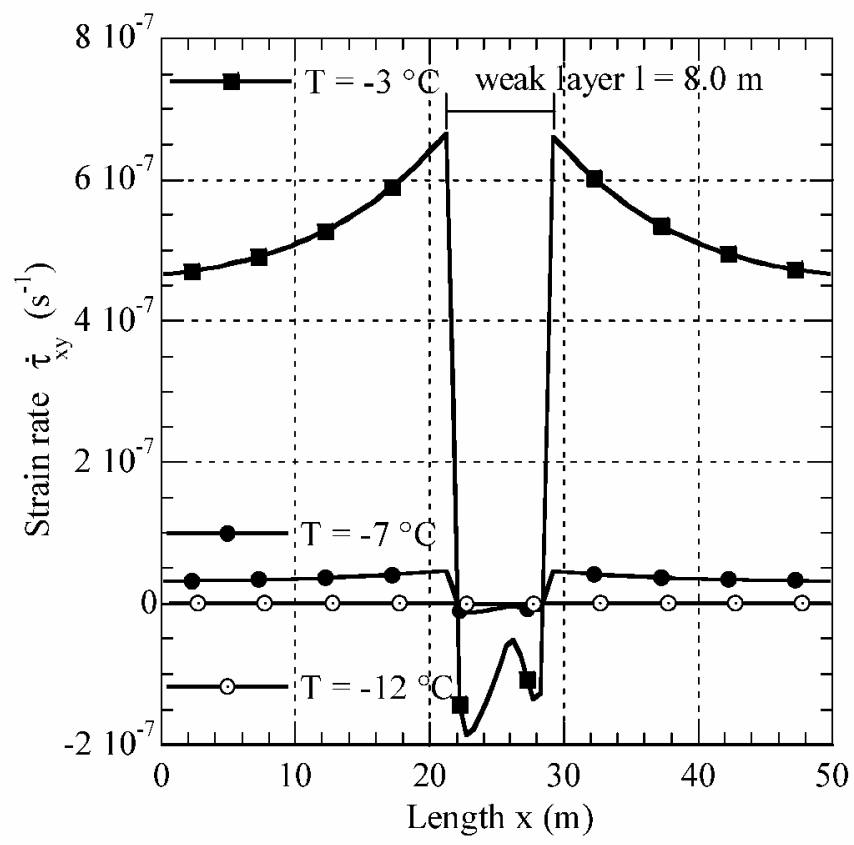

Fig. 8. Influence of the temperature on the strain-rate distribution along the weak layer. The properties of the simulated snowpack are shown in Figure 7. 
hardening effects due to physical processes, such as grain metamorphism, occurring in the snowpack. The development of the microstructural snowpack properties over time is contained in a one-dimensional numerical snowpack model (Lehning and others, 1998; Bartelt and Lehning, 2002) which now also contains the viscosity formulation listed above.

\section{GONGLUSIONS}

We observed that for high-density snow $\left(\rho>\sim 400 \mathrm{~kg} \mathrm{~m}^{-3}\right)$, Glen's law with material parameters similar to those for polycrystalline ice can be applied to model the viscous behaviour of snow. Conversely, we found that Glen's law with ice parameters cannot be applied to model snow with densities between $200 \mathrm{~kg} \mathrm{~m}^{-3} \leq \rho \leq 360 \mathrm{~kg} \mathrm{~m}^{-3}$. This complexity has not been taken into account in previous thermomechanical constitutive models. We believe that the large variation of the power-law parameters as a function of density is due to different deformation mechanisms occurring in the load-bearing ice skeleton. Although our constitutive model quantitatively fits the experimental results, it still cannot be applied to lower-density snow $\left(\rho<\sim 180 \mathrm{~kg} \mathrm{~m}^{-3}\right)$ or other snow types (e.g. faceted grains or depth hoar). The fracture properties of snow, important for avalanche formation, have also not been investigated.

Future experiments with higher strain rates and different snow types are required in order to provide a complete picture of the mechanical behaviour of snow. These results are still lacking for a predictive understanding of avalanche formation.

\section{AGKNOWLEDGEMENTS}

The authors would like to thank the Swiss National Science Foundation for the financial support of this work.

\section{REFERENGES}

Alley, R. B. 1986. Three-dimensional coordination number from twodimensional measurements: a new method. 7. Glaciol., 32(112), 391-396.

Bader, H. P. and B. Salm. 1990. On the mechanics of snow slab release. Cold Reg. Sci. Technol., 17 (3), 287-300.

Barnes, P., D. Tabor and J. C. F. Walker. 1971. The friction and creep of polycrystalline ice. Proc. R. Soc. London, Ser. A, 324(1557), 127-155.

Bartelt, P. and M. Christen. 1999. A computational procedure for instationary temperature-dependent snow creep. In Hutter, K., Y. Wang and H. Beer, eds. Advances in cold-region thermal engineering and sciences: technological, environ- mental, and climatological impact. Berlin, etc., Springer-Verlag, 367-386. (Lecture Notes in Physics 533.)

Bartelt, P. and M. Lehning. In press. A physical SNOWPACK model for the Swiss Avalanche Warning. Part I. Numerical model. Cold Reg. Sci. Technol.

Bartelt, P. and M. von Moos. 2000. Triaxial tests to determine a microstructurebased snow viscosity law. Ann. Glaciol., 31, 457-462.

Brown, R. L. 1980. A volumetric constitutive law for snow based on a neck growth model. 7. Appl. Phys., 51(1), 161-165.

Budd, W. F. and T. H. Jacka. 1989. A review of ice rheology for ice sheet modelling. Cold Reg. Sci. Technol., 16(2), 107-144.

Colbeck, S. C. 1998. Sintering in snow. [Abstract.] Eos, 79(17), Spring Meeting Supplement, S80.

Glen, J.W. 1955. The creep of polycrystalline ice. Proc. R. Soc. London, Ser. A, 228(1175), 519-538.

Goldsby, D. L. and D. L. Kohlstedt. 1997. Grain boundary sliding in finegrained ice I. Scripta Mater., 37(9), 1399-1406.

Gubler, H. 1978. Determination of the mean number of bonds per snow grain and of the dependence of the tensile strength of snow on stereological parameters. 7. Glaciol., 20(83), 329-341.

Jacka, T. H. 1994. Investigations of discrepancies between laboratory studies of the flow of ice: density, sample shape and size, and grain-size. Ann. Glaciol., 19, 146-154.

Lehning, M., P. Bartelt and B. Brown. 1998. Operational use of a snowpack model for the avalanche warning service in Switzerland: model development and first experiences. In Hestnes, E., ed. 25 Tears of Snow Avalanche Research, Voss 12-16 May 1998. Proceedings. Oslo, Norwegian Geotechnical Institute, 169-174. (NGI Publication 203.)

Mahajan, P. and R. L. Brown. 1993. A microstructure-based constitutive law for snow. Ann. Glaciol., 18, 287-294.

McClung, D. M. 1996. Effects of temperature on fracture in dry slab avalanche release. F. Geophys. Res., 101(B10), 21,907-21,920.

Mellor, M. 1975. A review of basic snow mechanics. International Association of Hydrological Sciences Publication 114 (Symposium at Grindelwald 1974 - Snow Mechanics), 251-291.

Mellor, M. and J. H. Smith. 1966. Creep of snow and ice. CRREL Res. Rep. 220.

Morgan, V. I. 1991. High-temperature ice creep tests. Cold Reg. Sci. Technol., 19 (3), 295-300.

Perla, R. 1977. Slab avalanche measurements. Can. Geotech. F., 14(2), 206-213. Russell-Head, D. S., W. F. Budd and P. J. Moore. 1984. Compacted snow as a pavement material for runway construction. Cold Reg. Sci. Technol., 9(3), $231-247$.

Schweizer, J. 1998. Laboratory experiments on shear failure of snow. Ann. Glaciol., 26, 97-102.

Sinha, N. K. 1979. Grain-size influence on effective modulus of ice. In Frederking, R., ed. Proceedings of Workshop on the Bearing Capacity of Ice Covers, 16-17 October 1978,Winnipeg, Manitoba. Ottawa, Ont., May, Snow and Ice Subcommittee, Associate Committee on Geotechnical Research, National Research Council of Canada, 65-79. (ACGR Technical Memorandum 123.)

Voytkovskiy, K. F. 1977. Mekhanicheskiye svoystva snega [Mechanical properties of snow]. Moscow, Nauka. Sibirskoye Otdeleniye. Institut Merzlotovedeniya. (Transl. by C. E. Bartelt.)

Weertman, J. 1973. Creep of ice. In Whalley, E., S. J. Jones and L. Gold, eds. Physics and chemistry of ice. Ottawa, Ont., Royal Society of Canada, 320-337.

Yosida, Z. and colleagues. 1955. Physical studies on deposited snow. I. Thermal properties. Contrib. Inst. Low Temp. Sci., Ser. A 7, 19-74 